\title{
Peran Tenaga Kesehatan Dan Dukungan Keluarga Terhadap Pengendalian Perilaku Merokok Lansia Perempuan Di Dieng Plateau
}

\section{The Role Of Health Personnel And Family Support On Smoking Behavior Control In Women Elderly In Dieng Plateau}

\author{
Dwi Widiyaningsih ${ }^{1}$, Rustiana Setyowati ${ }^{2}$ \\ ${ }^{12}$ Sekolah Tinggi Ilmu Kesehatan Surya Global \\ Email :widiya23juni@gmail.com, \\ Jln. Ringroad Selatan, Blado, Potorono, Banguntapan, Bantul, Yogyakarta)
}

\begin{abstract}
ABSTRAK
Merokok adalah penyebab hampir 90\% kanker paru, 75\% penyakit paru obstruktif kronis (PPOK), dan juga menjadi 25\% penyebab dari serangan jantung (Tobacco Atlas). Bangsa kita tidak kehilangan akal dalam mengendalikan perilaku merokok, berbagai upaya dilakukan mulai dari membuat UU, peraturan dan kebijakan bahkan sampai melakukan pendekatan yang komprehensif kepada keluarga sebagai panjang tangan program kesehatan selain dilakukan oleh tenaga kesehatan dalam upayanya untuk mengendalikan perilaku merokok, sebagaimana yang terjadi di dataran tinggi Dieng dimana perokok aktif $41 \%$ adalah kaum lansia dan yang lebih mencengangkan 29,5\% adalah lansia perempuan yang menempati peran penting dan dihormati dalam masyarakat karena status sosial yang tinggi dan budaya leluhur. Penelitian ini bertujuan mengidentifikasi pengaruh peran tenaga kesehatan dan dukungan keluarga terhadap pengendalian perilaku merokok lansia perempuan diwilayah dataran tinggi Dieng. Jenis penelitian ini adalah kuantitatif dengan pendekatan cross sectional. Populasi penelitian 125 lansia yang semuanya menjadi sampel (Total Sampling). Analisis data menggunakan Uji kendall tau dan Regresi linier berganda, dengan nilai dari uji Kendall Tau yaitu $(0,001<0,005)$ dan $(0,000<0,005)$ yang bermakna ada pengaruh yang signifikan, Sedangkan hasil Uii $F$ hitung 38,849 > F tabel 3,07 dengan tingkat signifikansi 0,000 $(\rho<0,005)$. Dapat disimpulkan semakin baik peran tenaga kesehatan dan dukungan keluarga maka semakin baik pengendalian perilaku merokok.
\end{abstract}

Kata kunci : Peran tenaga kesehatan; dukungan keluarga: merokok ;lansia perempuan; dieng

ABSTRACT

Smoking is the cause of nearly 90\% of lung cancers, $75 \%$ of chronic obstructive pulmonary disease (COPD), and it is also the cause of 25\% of heart attacks (Tobacco Atlas). Our nation has not lost its mind in controlling smoking behavior, various efforts have been made ranging from making laws, regulations and policies to even taking a comprehensive approach to the family as a long-handed health program besides being carried out by health workers in their efforts to control smoking behavior, as happened in Dieng plateau where $41 \%$ of active smokers are the elderly and what is even more astonishing $29.5 \%$ are elderly women who occupy important and respected roles in society because of their high social status and ancestral culture. This study is to identify the effect of the role of health workers and family support on the control of female elderly smokers in the Dieng highlands. This type of quantitative research with cross sectional approach. The study population was 125 elderly who were all sampled (total sampling technique). Data analysis used the test (Kendall tau) and multiple linear regression, with the value of the Kendall Tau test, namely $(0.001<0.005)$ and $(0.000<0.005)$ which means that there is a significant influence significant, while the results of the F test count $38.849>$ F table 3.07 with a significance level of $0.000(\rho<0.005)$. Concluded that the better the role of health workers and family support, the better the smoking behavior control.

Keywords: Role Of Health Personnel, Family Support, Smoking, Women’s Elderly, Dieng 


\section{PENDAHULUAN}

Tembakau dan turunannya masih menjadi topik yang menarik untuk diperbincangkan, bahkan dunia melalui WHO memberi perhatian lebih terhadapnya dengan menetapkan tanggal 31 mei 1988 sebagai hari bebas tembakau sedunia. WHO melaporkan bahwa penyebab kematian lebih dari 5 juta per tahun dan diperkirakan 10 juta tahun 2020, 70\% diantaranya berada dari negara berkembang disebabkan oleh penyakit akibat terpapar asap rokok tentu hal tersebut akan meningkatkan perhatian dunia.(WHO, 2019)

Meningkatnya perhatian ini juga disebabkan oleh tren yang menunjukkan perilaku merokok di beberapa Negara berkembang termasuk Indonesia cukup tinggi, bahkan ada kecenderungan semakin meningkat(Suharyanta et al., 2018). Indonesia menjadi negara terbesar ketiga pengguna rokok, lebih 70\% anak Indonesia terpapar asap rokok dan menanggung resiko terkena berbagai penyakit akibat asap rokok. Sedangkan penelitian Global Youth Tobacco menunjukkan tingkat prevelansi perokok remaja di Indonesia sudah sangat mengkhawatirkan. Diperkirakan dari 70 juta anak Indonesia, 37\% atau sama dengan 25,9 juta anak Indonesia adalah perokok, hal ini tentu tidak luput dari perilaku meniru dari seorang anak terhadap orang sekitar yang merokok, telebih orang yang memiliki pengaruh yaitu seorang ibu maupun nenek mereka. dan jumlah itu menjadikan Indonesia sebagai negara dengan jumlah perokok terbanyak di Asia. (Lian \& Dorotheo, 2019)

Fenomena perokok lansia perempuan didataran tinggi dieng yang menjadi salah satu destinasi wisata, menunjukan belum maksimalnya peran tenaga kesehatan dalam meningkatkan derajat kesehatan masyarakat dan gaya hidup sehat bagi masyarakat. Berdasarkan observasi yang peneliti lakukan ada 5 dari 12 orang tertarik ingin menyaksikan para lansia perempuan yang sedang menghisap rokok. Fakta secara mata telanjang memang kondisi para lansia perempuan yang merokok terlihat segar bugar dan sehat bahkan beberapa lansia yang kami jumpai tidak mengeluhkan gangguan pendengaran dan penglihatan mereka. Namun dibalik fakta tersebut menurut data dinas kabupaten Wonosobo terjadi peningkatan kejadian ISPA sebesar 32\% pada balita dan Jantung pada Wanita usia subur sebesar 37\% (Wonosobo, 2017).

Peran dukungan anggota keluarga dalam pengendalian perilaku merokok pada lansia perempuan diharapkan mampu mencegah berbagai resiko penyakit yang mungkin timbul pada anggota keluarga yang secara tidak langsung terpapar asap rokok terutama untuk balita, melalui anggota keluarga diharapkan perilaku merokok pada lansia perempuan akan terkendali. (Suharyanta et al., 2018). 
Dwi Widiyaningsih, Rustiana Setyowati : Peran Tenaga Kesehatan Dan Dukungan Keluarga Terhadap ,„,

\section{METODE}

Jenis penelitian yang digunakan adalah deskriptif kuantitatif. Penelitian ini dilaksanakan di Desa Dieng Wetan kecamatan Kejajar kabupaten Wonosobo pada bulan Juli sampai Oktober 2020. Populasi penelitian adalah lansia perempuan yang merokok berjumlah 125 orang dengan teknik pengambilan sampel menggunakan total sampling. Tehnik pengumpulan data menggunakan kuesioner dimana ini merupakan sumber data primer dengan penambahan wawancara terbuka sebagai data sekunder. Penelitian ini menggunakan pendekatan cross sectional. Analisis data menggunakan Uji analisis Bivariat (Kendall's Tau) untuk mengetahui adanya korelasi antara satu variabel dengan variabel lainnya, sedangkan untuk mengetahui pengaruh secara serempak variabel bebas terhadap variabel terikat maka uji yang sesuai adalah dengan menggunakan Uji Multivariat Regresi Linier Berganda dengan program SPSS 16.00.

\section{HASIL}

\section{Analisis Hasil Univariat}

Penelitian ini bertujuan mencari adanya pengaruh peran tenaga kesehatan dan peran dukungan keluarga terhadap pengendalian perilaku merokok pada lansia perempuan di dataran Tinggi Dieng, adapun dari hasil penelitian ini dapat diuraikan dalam tabel sebagai berikut :

\section{Tabel 1. Distribusi Frekuensi Responden}

\begin{tabular}{clrr}
\hline \multicolumn{1}{c}{ Variabel } & \multicolumn{1}{c}{ Kategori } & Jumlah & $\mathbf{( \% )}$ \\
\hline Kelompok umur & $60-69$ & 34 & 27.2 \\
& $70-79$ & 46 & 36.8 \\
\multirow{5}{*}{ Pendidikan } & $>80$ & 45 & 36.0 \\
& Tidak Sekolah & & \\
& SD & 87 & 69.6 \\
& SLTP & 36 & 28.8 \\
& SLTA & 2 & 1.6 \\
& PT & & \\
Pekerjaan & & & \\
& Ibu Rumah Tangga & 20 & 16.0 \\
& Pensiunan & & \\
& Buruh & 19 & 15.2 \\
& Petani & 25 & 20.0 \\
& Pedagang & 33 & 26.4 \\
& Wiraswasta & 28 & 22.4 \\
\hline & & 125 & 100 \\
\hline
\end{tabular}

Dari tabel diatas sebaran karakteristik responden berdasarkan usia lansia yaitu usia 60-69 tahun berjumlah 34 orang atau 27,2 \%, lansia yang berusia 70-79 tahun 
berjumlah 46 orang atau 36,8\%, lansia ber usia 80 tahun ke atas berjumlah 45 atau $36 \%$. Masyarakat dataran tinggi dieng secara pendidikan memang masih rendah terutama untuk masyarakat dari kalangan lansia, dari data diatas sebaran karakteristik responden berdasarkan jenjang pendidikan yaitu didominasi oleh lansia yang tidak bersekolah berjumlah 87 orang atau $69,6 \%$.

Persebaran pekerjaan responden hampir rata tidak ada yang mendominasi artinya sebagian lansia perempuan di daerah ini memilki pekerjaan yang beragam, berdasarkan hasil pengamatan peneliti, masyarakat desa Dieng khususnya dieng wetan kabupaten Wonosobo adalah pedagang dan petani kentang, mengingat Dieng adalah daerah pariwisata yang sangat membuka peluang bagi masyarakatnya untuk berdagang dan berwiraswasta sehingga profesi sebagai pedagang mendominasi pekerjaan responden. Pekerjaan terbanyak kedua adalah petani kentang karena daerah memiliki tanah yang sangat subur dan penghasil kentang terbesar di Jawa tengah, bahkan hasil bumi berupa kentang Dieng menjadi komoditas unggul yang banyak dicari dipasaran area Jawa Tengah, DIY bahkan sampai jawa barat dan Jakarta selain hasil bumi lainnya berupa sayur mayur dan buah khas Dieng yaitu Karika.

Penelitian ini untuk menganalisis ada tidaknya pengaruh antara setiap variabel independen dengan variabel dependen. Uji yang digunakan adalah Kendall's Tau karena setiap variabel merupakan data ordinal. Data yang didapatkan setelah di uji kerelasi menggunaakan program spss 16.00 adalah sebagai berikut :

\section{Tabel 2. Hasil Uji Kendall's Tau}

\begin{tabular}{cccc}
\hline No & Variabel & Correlation Coefisient & Signifikan \\
\hline 1 & Peran Tenaga Kesehatan & 0,387 & $0,001^{* *}$ \\
2 & Peran Dukungan Keluarga & 0,433 & $0,000^{* *}$ \\
\hline
\end{tabular}

Dari tabel 4 di atas mengenai hasil uji Kendall's tau pengaruh antara setiap variabel bebas dengan pengendalian perilaku merokok diketahui bahwa ada pengaruh yang signifikan antara Peran Tenaga Kesehatan terhadap Pengendalian Perilaku Merokok pada lansia perempuan di wilayah dataran tinggi Dieng. Hal ini dilihat dari nilai signifikannya (p) < 0,005 atau 0,001 < 0,005 yang berarti Ho ditolak dan Ha diterima yaitu ada korelasi Peran tenaga kesehatan dengan pengendalian perilaku merokok pada lansia perempuan. Dan hasil uji (r hitung) sebesar 0,387 yang berada pada interval 0,260,50 yang menandakan tingkat korelasinya sedang dan Nilai $r$ hitung mempunyai arah korelasi yang positif, bararti semakin mendukung Peran tenaga kesehatan semakin baik dalam pengendalian perilaku merokok pada lansia perempuan. 
Dwi Widiyaningsih, Rustiana Setyowati : Peran Tenaga Kesehatan Dan Dukungan Keluarga Terhadap ,„,

Ada pengaruh yang signifikan antara Peran Dukungan Keluarga terhadap Pengendalian Perilaku Merokok pada lansia perempuan di wilayah dataran tinggi Dieng Hal ini dilihat dari nilai signifikannya (p) $<0,005$ atau 0,000 $<0,005$ yang berarti Ho ditolak dan Ha diterima yaitu ada korelasi antara dukungan keluarga dengan pengendalian perilaku merokok pada lansia perempuan. Dan hasil uji (r hitung) sebesar 0,441 yang berada pada interval 0,26-0,50 yang menandakan tingkat korelasinya sedang dan didaptkan nilai $\mathrm{r}$ hitung mempunyai arah korelasi yang positif, bararti semakin mendukung keluarga dengan pengendalian perilaku merokok pada lansia perempuan semakin bagus pengendalian perilaku merokok.

\section{PEMBAHASAN}

Hasil penelitian mengungkapkan adanya pengaruh yang signifikan antara peran tenaga kesehatan dengan pengendalian perilaku merokok pada lansia perempuan di wilayah dataran tinggi Dieng. Hal ini senada dengan penelitian (Suharyanta et al., 2018), salah satu upaya pencegahan yang efektif adalah adanya pendekatan dari tenaga kesehatan dimana tenaga kesehatan merupakan orang yang disegani oleh masyarakat. Dengan rasa segan maka jika lansia mendapatkan nasihat dari petugas kesehatan yang dijumpainya maka secara berangsur akan mematuhi apa yang disampikan oleh tenaga kesehatan tersebut. Sebagaimana dalam buku "Ngudud” (Budhi Santosa, 2012), me time nya orang jawa adalah dengan merokok untuk melepas penat dan beban hidup wong cilik, sehingga dalam memberikan edukasi larangan berhenti merokok harus melalui pendekatan-pendekatan sebagaimana hal ini merupakan strategi dalam promosi kesehatan, dan salah satu tugas pokok tenaga kesehatan adalah Promosi kesehatan. Pendekatan juga sangat dibutuhkan dalam melakukan konseling agar perubahan perilaku yang kita harapkan akan efektif (Notoatmodjo, 2014), mengingat merokok di dataran tinggi dieng merupakan tradisi turun temurun (Widiyaningsih, 2020) yang sudah ada sejak zaman penjajahan. Sementara dalam penelitian (Daroji et al., 2011) mengungkapkan bahwa peran petugas kesehatan diyakini bisa mencapai 10\% dalam mendorong pasien untuk berhenti merokok, yakni dengan memberikan instruksi yang tegas kepada pasien perokok untuk tidak meneruskan kebiasaannya.

Perilaku merokok ini tentunya sudah berulang kali mendapat perhatian khusus dari pemerintah baik pusat sampai pemerintah daerah sekalipun dengan dikeluarkannya berbagai macam aturan dan Undang-Undang terkait rokok, serta berbagai program kesehatan yang dicanangkan oleh negara kita dengan memaksimalkan sumber daya 
manusia di bidang kesehatan diantaranya adalah tenaga Promotor kesehatan. Dimana kita mengetahui bahwa Tugas pokok tenaga kesehatan adalah preventif, promotif, kuratif dan rehabilitatif, Dalam penelitian yang dimaskud peran tenaga kesehatan adalah tenaga kesehatan yang melakukan peranya sebagai promotor kesehatan dan preventif, pencegahan merokok merupan salah satu tugas tenaga kesehatan untuk mengurangi prevalensi perokok.

Menilik analisa bivariat pada penelitian ini dapat dilihat nilai signifikannya (p) < 0,005 atau 0,001 < 0,005 yang berarti Ho ditolak dan Ha diterima yaitu ada korelasi Peran tenaga kesehatan dengan pengendalian perilaku merokok pada lansia perempuan. Dan hasil uji ( $\mathrm{r}$ hitung) sebesar 0,387 yang berada pada interval 0,26-0,50 yang menandakan tingkat korelasinya sedang dan Nilai $\mathrm{r}$ hitung mempunyai arah korelasi yang positif, bararti semakin mendukung peran tenaga kesehatan semakin baik dalam pengendalian perilaku merokok pada lansia perempuan.

Hasil penelitian dijelaskan bahwa ada pengaruh yang signifikan antara Peran Dukungan Keluarga dengan Pengendalian Perilaku Merokok pada lansia perempuan di wilayah dataran tinggi Dieng Hal ini dilihat dari nilai signifikannya (p) $<0,005$ atau $0,000<0,005$ yang berarti Ho ditolak dan Ha diterima yaitu ada korelasi antara dukungan keluarga dengan pengendalian perilaku merokok pada lansia perempuan. Dan hasil uji (r hitung) sebesar 0,441 yang berada pada interval 0,26-0,50 yang menandakan tingkat korelasinya sedang dan didaptkan nilai r hitung mempunyai arah korelasi yang positif, bararti semakin mendukung keluarga dengan pengendalian perilaku merokok pada lansia perempuan semakin bagus pengendalian perilaku merokok.

Pengendalian perilaku merokok menjadi tanggung jawab bersama mengingat dampak akibat asap rokok sangat berbahaya, sebaiknya memang melibatkan segala lini dan sektor mulai dari lingkungan rumah yaitu menghadirkan dan memaksimalkan keluargaa dalam pencegahan perilaku merokok, sehingga kemudahan dalam pengendalian akan tercipta.dalam hal ini pengendalian perilaku merokok pada lansia perempuan dalam sebuah rumah juga akan berdampak pada perilaku generasi penerusnya dalam rumah tersebut, dalam keluarga di mana orangtua dan saudara kandung tidak merokok dan melakukan pencegahan merokok, akan menurunkan risiko merokok pada remaja. Anak akan belajar dari apa yang dilakukan orangtua bukan apa yang dikatakan orang tua. Sehingga jika orang tua dan saudara tua merokok maka kemungkinan besar anak juga akan merokok. Remaja yang memiliki orang tua perokok memiliki risiko lebih tinggi untuk menjadi perokok daripada remaja yang dengan orangtua bukan perokok (Rachmat 
Dwi Widiyaningsih, Rustiana Setyowati : Peran Tenaga Kesehatan Dan Dukungan Keluarga Terhadap ,„,

et al., 2013). Tentunya jika perilaku merokok lansia perempuan dalam sebuah rumah berkurang maka akan dicontoh oleh anggota keuarga yang lan yang lebih muda seperti anak dan cucu.

Hal ini sesuai dengan yang dikemukakan oleh (Tarwoto, 2010), faktor yang mempengaruhi kebiasaan merokok salah satunya adalah peran orangtua (orang tua yang tinggal satu rumah termasuk nenek, kakek). Anak-anak muda yang berasal dari rumah tangga yang tidak bahagia, dimana orang tua begitu memperhatikan anak-anaknya dan memberikan hukuman fisik yang keras, lebih mudah untuk menjadi perokok di bandingkan anak-anak muda yang berasal dari lingkungan rumah tangga yang bahagia.

Yang kuat pengaruhnya adalah bila orangtua sendiri menjadi figure contoh, yaitu sebagai perokok berat, maka anak-anaknya akan mungkin sekali untuk mencontohnya (Tarwoto, 2010). Begitu juga sebaliknya jika orang tua menerapkan aturan tegas dan melakukan pengawasan serta menjadi orang tua yang penuh perhatian dan kasih sayang kepada anak maka pencegahan perilaku merokok juga akan ssangat mudah dipatuhi oleh sang anak, terlebih dengan figur orang tua yang tidak merokok maka akan akan memudahkan bagi sang anak untuk patuh dan mencontoh perilaku orang tua. Meskipun pengaruh peran dukungan keluarga merupakan prediktor penting bagi pengendalian perilaku merokok pada lansia, namun hal tersebut tidak dapat dipisahkan dari faktor lain yang mempengaruhi pencegahan perilaku merokok.

Berdasarkan hasil analisis regresi linier berganda dengan menggunakan program SPSS 16.0 diperoleh hasil uji f hitung sebesar 38.849 dan tingkat signifikansi sebesar 0,000. Signifikansi tersebut lebih kecil dari alpha $(0,000<0,005)$ yang berarti kedua variabel bebas yaitu peran tenaga kesehatan dan peran dukungan keluarga berpengaruh terhadap pengendalian perilaku merokok pada lansia perempuan, adapun tingkat koefisiensi menunjukan korelasi yang kuat yaitu dengan nilai R 784.

Angka kematian akibat penyakit yang disebabkan oleh rokok di Indonesia semakin meningkat bahkan prevalensi perokok Indonesia tidak pernah mengalami penurunan sejak tahun 1980-2013(Mathur et al., 2014). Terdapat sekitar 5,8 triliun perokok di seluruh dunia, 176 juta diantaranya adalah wanita jumlah perokok wanita semakin meningkat khususnya pada usia remaja(Wipfli, 2012). Hal ini dipicu karena kecenderungan meniru kepada orang sekitarnya terutama seorang ibu dalam sebuah penelitian ditemukan enam hal utama terkait perilaku merokok pada wanita : 1) awal mula perilaku merokok pada wanita; 2) proses perilaku merokok wanita; 3) pengetahuan dampak merokok pada wanita; 4) pandangan terhadap nilai-nilai perilaku merokok 
wanita; 5) ketersediaan informasi mengenai dampak rokok dari tenaga kesehatan; dan 6) pengaruh panutan.

Menurut Widiyaningsih, 2020, di wilayah dieng perilaku merokok pada lansia merupakan pemandangan yang biasa dan sudah menjadi lumrah bahkan mereka akan bebas dan leluasa merokok didalam rumah yang notabene didalamnya terdapat anak balita sehingga dijumpai banyak sekali kejadian ISPA di daerah ini (Wonosobo, 2017). Belum lagi alibi bahwa meskipun merokok mereka sehat senada dengan pernyataan sebuah penelitian bahwa pengalaman dampak merokok. Sebagian perokok wanita merasa sehat dan tidak merasakan dampak merokok. Hal ini disebut sebagai risk-exempting belief yaitu keyakinan bebas risiko dari merokok yang dilakukan. Seseorang yang mempunyai health belief yang kuat akan mengarahkan perilakunya menuju perilaku yang membuat tubuhnya sehat.(Yesa, 2017).

Kebiasaan yang dilakukan lansia perempuan di dataran tinggi dieng ini dilakukan setelah mereka melakukan aktivitas fisik dalam pekerjaan mereka,seperti naik gunung untuk mencari kayu bakar, ke kebun kentang atau setelah menikmati hidangan maka mereka akan segera merokok, menurut mereka kenikmatan perokok wanita adalah merokok setelah makan, bila tidak merokok setelah makan justru terasa pahit. Padahal ini adalah bentuk kebiasaan yang berubah menjadi candu akibat kandungan nikotin rokok (Hong et al., 2015).

Kondisi berkumpul dengan komunitas lansia atau warga yang merokok juga akan membuat lansia semakin banyak dalam menghisap rokok hal ini sebagaimana diceritakan oleh salah seorang responden yang kami wawancarai. Perempuan perokok dilaporkan menjadi percaya diri, suka menentang, dan secara sosial cakap (Suhta, 2018). Perokok wanita merasa di satu pihak pemerintah melarang untuk merokok, namun kenyataan di kehidupan sehari-hari perokok wanita masih menemukan rokok dijual bebas. Rokok merk baru bermunculan dengan harga lebih murah. Indonesia adalah salah satu negara Islam, seharusnya membuat kebijakan yang tegas terhadap rokok karena telah diharamkan dalam agama Islam, namun karena industri rokok merupakan penyerap kedua terbesar untuk tenaga kerja, hal ini membuat Indonesia tidak bisa menghentikan produksi rokok.(Karini \& Padmawati, 2018) mantan perokok akan kembali merokok bila berada di lingkungan sekitar orang-orang yang merokok (Orton et al., 2016). 
Dwi Widiyaningsih, Rustiana Setyowati : Peran Tenaga Kesehatan Dan Dukungan Keluarga Terhadap ,„,

\section{SIMPULAN}

Kesimpulan dalam penelitian ini secara serempak ada pengaruh yang kuat antara peran tenaga kesehatan dan dukungan keluarga terhadap pengendalian perilaku merokok pada lansia perempuan di wilayah dataran tinggi Dieng dengan nilai Uji F hitung 38,849 > F tabel 3,07 dan nilai R 784 (korelasi yang kuat). Sedangkan jika dengan analisis bivariat masing-masing variabel bebas mempunyai pengaruh yang signifikan dengan ditujunjukan dengan nilai signifikan pada variabel peran tenaga kesehatan sebesar 0,001 $<0,005$ atau (p) < 0,005 dengan nilai r 0,387 (korelasi sedang) dan untuk variabel dukungan keluarga nilai signifikannya (p) $<0,005$ atau 0,001 $<0,005$ dengan nilai r 0,433 (Korelasi sedang).

\section{UCAPAN TERIMA KASIH}

Ucapan terimakasih yang sebesar-besarnya kami sampaikan kepada 1) Direktorat

Riset dan Pengabdian Masyarakat Direktorat Jenderal Penguatan Riset dan Pengembangan Kementerian Riset, Teknologi dan Pendidikan Tinggi, 2) LLDIKTI Wilayah V, 3) Kecamatan Kejajar, 4) STIKes Surya Global Yogyakarta.

\section{DAFTAR PUSTAKA}

Budhi Santosa, I. (2012). Ngudud: Cara Orang Jawa Menikmati Hidup. Manasuka.

Daroji, M., Prabandari, Y. S., \& Paramastri, I. (2011). Peran Petugas Puskesmas dalam Promosi Kesehatan Berhenti Merokok pada Pasien dan Masyarakat. Berita Kedokteran Masyarakat, 27(2), 83-93.

Hong, R. M., Guo, S. E., \& Chen, M. Y. (2015). The experiences of tobacco use among South-western taiwanese adolescent males. International Journal of Environmental Research and Public Health, 12(9), 10522-10535. https://doi.org/10.3390/ijerph120910522

Karini, T. A., \& Padmawati, R. S. (2018). Fenomena sosial unik pada perokok wanita di kabupaten Lebong Bengkulu Indonesia. Berita Kedokteran Masyarakat, 34(1), 1924. https://media.neliti.com/media/publications/237887-none-034f3c75.pdf

Lian, T., \& Dorotheo, U. (2019). The Tobacco Control Atlas: ASEAN Region, Fourth Edition. In Clove Cigarettes May Prompt U.S., Indonesia Dispute (Issue September). https://seatca.org/clove-cigarettes-may-prompt-u-s-indonesia-dispute/

Mathur, C., Stigler, M. H., Erickson, D. J., Perry, C. L., \& Forster, J. L. (2014). Transitions in smoking behavior during emerging adulthood: A longitudinal analysis of the effect of home smoking bans. American Journal of Public Health, 104(4), 715-720. https://doi.org/10.2105/AJPH.2013.301642

Notoatmodjo, S. (2014). Ilmu Perilaku Kesehatan (p. 173). Rineka Cipta.

Orton, S., Coleman, T., Lewis, S., Cooper, S., \& Jones, L. L. (2016). "I was a full time proper smoker": A qualitative exploration of smoking in the home after childbirth among women who relapse postpartum. PLoS ONE, 11(6), 1-16. https://doi.org/10.1371/journal.pone.0157525 
Rachmat, M., Thaha, R. M., \& Syafar, M. (2013). Perilaku Merokok Remaja Sekolah Menengah Pertama. Kesmas: National Public Health Journal, 7(11), 502. https://doi.org/10.21109/kesmas.v7i11.363

Suharyanta, D., Widiyaningsih, D., \& Sugiono. (2018). Peran Orang Tua , Tenaga Kesehatan , Dan Teman Sebaya Terhadap Pencegahan Perilaku Merokok Remaja. Jurnal Manajemen Kesehatan Yayasan RS Dr. Soetomo, 4(1), 8-13. https://doi.org/http://dx.doi.org/10.29241/jmk.v4i1

Suhta, D. W. (2018). Pengetahuan dan Perilaku Merokok Pelajar Sekolah Menengah Pertama. Jurnal Manajemen Kesehatan Yayasan RS.Dr. Soetomo, 4(1), 47. https://doi.org/10.29241/jmk.v4i1.101

Tarwoto. (2010). Kebutuhan Dasar Manusia Dan Proses Keperawatan (4th ed.). Salemba Medika.

WHO. (2019). Tubuh tembakau. 1. WHO/NMH/PND/19.1

Widiyaningsih, D. (2020). Pengaruh Sosial Budaya Dan Geografis Terhadap Perilaku Merokok Pada Lansia Perempuan Di Wilayah Dataran Tinggi Dieng Wonosobo. Jurnal Manajemen Kesehatan Yayasan RS Dr. Soetomo, 6(2).

Wipfli, H. (2012). The Tobacco Atlas, Fourth Edition. American Journal of Epidemiology, 176(12), 1193-1193. https://doi.org/10.1093/aje/kws389

Wonosobo, D. (2017). “Bersatu Mewujudkan Wonosobo Sehat” 2017 (Issue 02).

Yesa, K. (2017). Studi Deskriptif di Kota Bandung Mengenai Health Belief pada Perokok Berat. Prosiding Psikologi, 3(2), 342-347.

\begin{tabular}{|l|l|}
\hline Submission & 11 Oktober 2020 \\
\hline Review & 11 Januari 2021-04 Maret 2021 \\
\hline Accepted & 05 Maret 2021 \\
\hline Publish & 12 April 2021 \\
\hline DOI & 10.29241/jmk.v7i1.570 \\
\hline Sinta Level & Tiga (3) Nasional Akreditasi \\
\hline
\end{tabular}

